\section{RESEARCH PAPER}

\section{Investigation of the}

distribution and function of $\alpha$-adrenoceptors in the

\section{sheep isolated internal anal sphincter}

\author{
SJ Rayment ${ }^{1}$, T Eames ${ }^{1}$, JAD Simpson ${ }^{1}$, MR Dashwood ${ }^{2}$, Y Henry ${ }^{3}$, \\ H Gruss $^{3}$, AG Acheson ${ }^{1}$, JH Scholefield ${ }^{1}$ and VG Wilson ${ }^{4}$ \\ ${ }^{1}$ Centre for Integrated Systems Biology and Medicine, Department of Surgery and ${ }^{4}$ School of \\ Biomedical Sciences, The University of Nottingham Medical School, Queen's Medical Centre, \\ Clifton Boulevard, Nottingham, UK, ${ }^{2}$ Clinical Biochemistry, Royal Free and University College \\ Medical School, Royal Free Campus, London, UK, and ${ }^{3}$ Clinical Development, Norgine Ltd, R\&D \\ Division, Harefield, UK
}

\section{Correspondence}

Dr VG Wilson, School of Biomedical Sciences, The University of Nottingham Medical School, Queen's Medical Centre, Clifton Boulevard, Nottingham NG7 2UH, UK. E-mail: vince.wilson@nottingham.ac.uk

\section{Keywords}

imidazoline; faecal incontinence; radioligand binding; L-erythro-methoxamine

\section{Received}

7 January 2010

Revised

16 March 2010

Accepted

22 March 2010

\title{
BACKGROUND AND PURPOSE
}

We have investigated the distribution of $\alpha$-adrenoceptors in sheep internal anal sphincter (IAS), as a model for the human tissue, and evaluated various imidazoline derivatives for potential treatment of faecal incontinence.

\section{EXPERIMENTAL APPROACH}

Saturation and competition binding with ${ }^{3} \mathrm{H}$-prazosin and ${ }^{3} \mathrm{H}-\mathrm{RX} 821002$ were used to confirm the presence and density of $\alpha$-adrenoceptors in sheep IAS, and the affinity of imidazoline compounds at these receptors. A combination of in vitro receptor autoradiography and immunohistochemistry was used to investigate the regional distribution of binding sites. Contractile activity of imidazoline-based compounds on sheep IAS was assessed by isometric tension recording.

\section{KEY RESULTS}

Saturation binding confirmed the presence of both $\alpha_{1}$ - and $\alpha_{2}$-adrenoceptors, and subsequent characterization with sub-type-selective agents, identified them as $\alpha_{1 A^{-}}$and $\alpha_{2 D^{2}}$-adrenoceptor sub-types. Autoradiographic studies with ${ }^{3} \mathrm{H}$-prazosin showed a positive association of $\alpha_{1}$-adrenoceptors with immunohistochemically identified smooth muscle fibres.

Anti- $\alpha_{1}$-adrenoceptor immunohistochemistry revealed similar distributions of the receptor in sheep and human IAS. The imidazoline compounds caused concentration-dependent contractions of the anal sphincter, but the maximum responses were less than those elicited by L-erythro-methoxamine, a standard non-imidazoline $\alpha_{1}$-adrenoceptor agonist. Prazosin (selective $\alpha_{1}$-adrenoceptor antagonist) significantly reduced the magnitude of contraction to L-erythro-methoxamine at the highest concentration used. Both prazosin and RX811059 (a selective $\alpha_{2}$-adrenoceptor antagonist) reduced the potency $\left(\mathrm{pEC}_{50}\right)$ of clonidine.

\section{CONCLUSIONS AND IMPLICATIONS}

This study shows that both $\alpha_{1}$ - and $\alpha_{2}$-adrenoceptors are expressed in the sheep IAS, and contribute (perhaps synergistically) to contractions elicited by various imidazoline derivatives. These agents may prove useful in the treatment of faecal incontinence.

\section{Abbreviation}

IAS, internal anal sphincter 


\section{Introduction}

Faecal incontinence is a common condition which, depending on criteria applied, affects up to $2 \%$ of the population (Perry et al., 2002) and can have a devastating effect on quality of life. Clinical management of the condition has historically relied on non-pharmacological approaches, although there is increasing interest in modulating the contractile state of the anal sphincter smooth muscle to alleviate symptoms (Tuteja and Rao, 2004).

It has long been recognized that sympathetic activation of $\alpha$-adrenoceptors contributes to continence in man (Parks et al., 1969; Frenckner and Ihre, 1976). In 1975, Gutierrez and Shah reported that intravenous infusion or oral administration of $\alpha$-adrenoceptor antagonists caused a reduction in anal sphincter pressure (Gutierrez and Shah, 1975). Similarly, the selective $\alpha_{1}$-adrenoceptor antagonist indoramin caused a reduction in anal sphincter pressure in patients suffering from anal fissures (Pitt et al., 2001). These observations are consistent with reports on isolated segments of the human internal sphincter that $\alpha_{1}$-adrenoceptors mediate constriction (Speakman et al., 1990; Glavind et al., 1997). Several recent clinical trials have been conducted to examine the effect of $\alpha$-adrenoceptor agonists on anal sphincter pressure in both healthy volunteers and patients (Carapeti et al., 1999; 2000; Cheetham et al., 2001; Badvie and Andreyev, 2005; Park et al., 2007). Anal (topical) application of the selective $\alpha_{1}$-adrenoceptor agonist phenylephrine was found to cause a significant increase in resting anal pressure in healthy volunteers (Carapeti et al., 1999). Subsequent use of this agonist in patients with faecal incontinence noted a significant increase in maximum resting pressures, but only when phenylephrine was employed at higher concentrations $(10 \% \mathrm{w} / \mathrm{w})$ than in volunteers and which may account for the incidence of local side effects (Carapeti et al., 2000). Later trials with patients suffering with passive faecal incontinence (Cheetham et al., 2001), radiation-induced faecal incontinence (Badvie and Andreyev, 2005) and incontinence resulting from low anterior resection (Park et al., 2007) produced mixed results. Based on incontinence scoring, radiation-induced faecal incontinence was improved by $10-20 \% \quad(w / w)$ phenylephrine (Badvie and Andreyev, 2005), while a $30 \%(\mathrm{w} / \mathrm{w})$ gel was insufficient to improve the continence scores or resting pressure of low anterior resection patients (Park et al., 2007). Conversely, in patients suffering with passive faecal incontinence, $30 \%(\mathrm{w} / \mathrm{w})$ phenylephrine gel was sufficient to increase resting pressure (Cheetham et al., 2001).
Mortensen and colleagues reported that an isomer of methoxamine, L-erythro-methoxamine, was four times more potent than phenylephrine as a constrictor agent in the porcine isolated internal anal sphincter (IAS) in vitro (Jones et al., 2003). Based on these findings, trials have been conducted in human volunteers and patients. Intra-anal and rectal application of L-erythro-methoxamine gel in healthy volunteers demonstrated rapid and sustained increase in resting pressure from a concentration as low as $1 \% \mathrm{w} / \mathrm{w}$ (Nisar et al., 2005). Furthermore, when 1\% gel preparations were applied to patients suffering with faecal incontinence, resting pressures similarly increased rapidly and gave a sustained response (Nisar et al., 2007). However, application of 3\% L-erythro-methoxamine in an immediate release formulation was associated with an increased systemic absorption and side effects of hypertension and bradycardia in some patients.

The potential role of $\alpha_{2}$-adrenoceptors in faecal continence has not been explored in man, but work in the anaesthetized opossum suggests that the imidazoline derivative clonidine can activate the myenteric neurones responsible for inhibition of the recto-anal inhibitory reflex (Yamato and Rattan, 1990). Although there are no comparable studies in man, $\alpha_{2}$-adrenoceptors are known to be present in the duodenum and proximal colon (Zhang et al., 1992; Valet et al., 1993), and administration of selective $\alpha_{2}$-adrenoceptor agonists (e.g. clonidine) is associated with an increase in colonic and rectal compliance (Viramontes et al., 2001; Camilleri et al., 2003). Interestingly, $\alpha_{2}$-adrenoceptors have been reported to play a role in noradrenaline-mediated constriction of the pig isolated IAS, but only at high concentrations, suggesting that $\alpha_{1}$-adrenoceptors are predominant in contractile responses to $\alpha$ adrenoceptor agonists (Mills et al., 2008).

As changes in modern surgical practice have led to a significant increase in sphincter-preserving surgery which allows the post-operative patient to maintain voluntary continence, access to human tissue is limited. With this in mind, the current study has utilized a sheep model of the IAS to characterize the $\alpha$-adrenoceptors in sheep IAS, and used this model to investigate potential pharmacological tools for the therapeutic treatment of faecal incontinence. The aim of the current study was twofold. First, to establish the presence and where possible the distribution of $\alpha$-adrenoceptors in sheep and human IAS; and second, to investigate whether a variety of imidazoline compounds compared to known $\alpha_{1}$-adrenoceptor agonists exhibit functional effects at $\alpha$-adrenoceptors expressed in sheep IAS. 


\section{Methods}

Human IAS tissue was collected in accordance with ethical approval obtained from the University of Nottingham Ethics committee (05/Q2403/171) from patients undergoing a proctectomy either as part of an abdominoperineal resection or completion procedure as a consequence of suffering from ulcerative colitis. Care was taken to ensure that none of the patients had active disease affecting the anal canal at the time of operation.

Sheep anus, containing IAS and rectum, were obtained from a local abattoir and transported to the lab on ice within $120 \mathrm{~min}$ and stored at $4^{\circ} \mathrm{C}$. Within a further $2 \mathrm{~h}$, the anal canal was divided along its ventral longitudinal axis and pinned to a corkboard with the mucosa uppermost. The mucosa was reflected at the dentate line to expose the underlying white circular muscle fibres of the IAS. Further dissection from the underlying external sphincter enabled a thin strip of circular internal sphincter to be prepared. The IAS was dissected and used for the following experiments.

\section{Radioligand binding experiments}

Sheep IAS was dissected from anal tissue on the day of collection and frozen at $-20^{\circ} \mathrm{C}$ until required. When required, the defrosted tissue was crudely chopped and homogenized using an Omni macro homogenizer (Omni International, Kennesaw, GA, USA) in a minimal volume of ice-cold buffer (50 mM, Tris- $\mathrm{HCl} \mathrm{pH} \mathrm{7.6).} \mathrm{Tissue} \mathrm{typically} \mathrm{required}$ three $30 \mathrm{~s}$ homogenizations at maximum speed to achieve complete tissue disruption. Ice-cold Tris buffer was used to increase the homogenate volume to 10 times original tissue wet weight before centrifugation at $1500 \times g$ for $10 \mathrm{~min}$ at $4^{\circ} \mathrm{C}$. The supernatant was passed through a gauze filter then centrifuged at $30000 \times \mathrm{g}$ for $30 \mathrm{~min}$ at $4^{\circ} \mathrm{C}$. The resulting pellet was then washed and resuspended in 2 volumes tissue wet weight of ice-cold Tris buffer. Following radioligand binding, fractions of membrane preparations were retained and stored at $-20^{\circ} \mathrm{C}$ for estimation of protein concentration by Lowry assay (Lowry et al., 1951). In all cases, membrane preparations were made from frozen tissue and used for experiments on the same day, because preliminary experiments had previously revealed that if frozen membrane preparations were used, they failed to reveal significant binding of the ligands.

Saturation binding with $\left[{ }^{3} \mathrm{H}\right]$-prazosin (selective antagonist for $\alpha_{1}$-adrenoceptors) was performed in a $500 \mu \mathrm{L}$ reaction volume consisting of $200 \mu \mathrm{L}$ membrane preparation; $200 \mu \mathrm{L} 50 \mathrm{mM}$ Tris- $\mathrm{HCl}, \mathrm{pH} 7.6$; $50 \mu \mathrm{L}$ of $50 \mathrm{mM}$ TE buffer (50 mM Tris, $1 \mathrm{mM}$ EDTA,
$\mathrm{pH}$ 7.4) or $100 \mu \mathrm{M}$ noradrenaline (used to define non-specific binding) and $50 \mu \mathrm{L}\left[{ }^{3} \mathrm{H}\right]$-prazosin using eight doubling concentrations in a range of 0.04$5 \mathrm{nM}$ (final concentration). Reactions were initiated by the addition of membrane preparation, and after thorough mixing, were incubated at $25^{\circ} \mathrm{C}$ for $30 \mathrm{~min}$. Reactions were terminated by filtration under vacuum using a Brandel cell harvester (Semat, Herts, UK). Filters were washed three times with ice-cold TE buffer to remove unbound radioligand, and remaining bound ligand was evaluated by scinitillation counting. All experiments were performed in triplicate. Saturation studies with $\left[{ }^{3} \mathrm{H}\right]-\mathrm{RX} 821002$ (a selective antagonist for $\alpha_{2}$-adrenoceptors) were performed as described above, but rauwolscine $(100 \mu \mathrm{M}$ final concentration) was used instead of noradrenaline, to define non-specific binding. Binding reactions were incubated for $60 \mathrm{~min}$ rather than $30 \mathrm{~min}$, and the concentration range for $\left[{ }^{3} \mathrm{H}\right]-\mathrm{RX} 821002$ was 0.08 $10 \mathrm{nM}$. These conditions have been used in previous studies using these radioligands (Wright et al., 1995). Competition studies using $\left[{ }^{3} \mathrm{H}\right]$-prazosin and $\left[{ }^{3} \mathrm{H}\right]-\mathrm{RX} 821002$ were performed in a $500 \mu \mathrm{L}$ volume using $200 \mu \mathrm{L}$ membrane preparation, $200 \mu \mathrm{L} 50 \mathrm{mM}$ Tris- $\mathrm{HCl}, 50 \mu \mathrm{L}\left[{ }^{3} \mathrm{H}\right]$-antagonist at a fixed concentration and $50 \mu \mathrm{L}$ of competitor at increasing concentrations. The relative affinities of seven different imidazoline derivatives at $\alpha_{1}$ - and $\alpha_{2}$-adrenoceptors were compared to L-erythro-methoxamine and nordrenaline using competition binding.

\section{Immunohistochemistry}

Strips of sheep and human circular IAS were embedded in OCT (BDH, Poole, Dorset, UK), and sections $(10 \mu \mathrm{m}$ thick) were cut in a cryostat at approximately $-20^{\circ} \mathrm{C}$ and thaw-mounted on poly-lysinecoated slides. Immunohistochemical staining of sections proceeded according to instructions for Vectastain ABC-AP kit (Vector laboratories Inc., Burlingame, CA, USA). Briefly, sections were allowed to equilibrate to room temperature prior to fixation in cold acetone at $-20^{\circ} \mathrm{C}$ for $20 \mathrm{~min}$. After residual fixative had evaporated, slides were incubated in phosphate-buffered saline (PBS) containing 10\% normal horse serum and incubated at room temperature for $10 \mathrm{~min}$ in humid conditions to block non-specific binding. All subsequent incubations were also carried out at room temperature in humid conditions. After removing the blocking solution, the slides were incubated in PBS (negative control) or PBS containing one of the following antibodies for 30 min: anti- $\alpha$-smooth muscle actin (1:200 dilution; to identify smooth muscle cells), anti-CD31 (1:100; endothelial cell marker), anti-NF200 (1:200; for identification of neurones), anti-tyrosine 
hydroxylase (1:250; adrenergic neurone marker) or anti- $\alpha_{1 \mathrm{~A}}$-adrenoceptor (1:400; Genway Biotech Inc., San Diego, CA, USA). The slides were washed three times in PBS before incubating with biotinylated universal antibody in blocking solution (as per manufacturer's instructions) for $10 \mathrm{~min}$ before washing three times in PBS again and incubating with the ABC-AP reagent for $5 \mathrm{~min}$. The slides were once again washed three times in PBS before development with alkaline phosphatase substrate solution (in $200 \mathrm{mM}$ Tris buffer, $\mathrm{pH}$ 8.2). Reactions were terminated by immersion and rinsing in water.

The slides were subsequently counterstained with haematoxylin for $15 \mathrm{~s}$, rinsed in running tap water, dehydrated in increasing concentrations of methanol, clearing in Histoclear (National Diagnostics, Hull, UK) and coverslipped using DPX mountant (BDH). A minimum of three tissues (two non-consecutive sections from each tissue) were evaluated for each antibody used.

\section{Autoradiography}

Sections of sheep IAS $(10 \mu \mathrm{m})$ were thaw-mounted on poly-lysine-coated slides as described for the immunohistochemistry, and pre-incubated in $50 \mathrm{mM}$ Tris- $\mathrm{HCl}, \mathrm{pH} 7.6$, for $10 \mathrm{~min}$ at $4^{\circ} \mathrm{C}$ to remove endogenous ligand. The sections were then transferred to $50 \mathrm{mM}$ Tris- $\mathrm{HCl}, \mathrm{pH} 7.6$, containing $5 \mathrm{nM}{ }^{3} \mathrm{H}$-prazosin, then incubated for $1 \mathrm{~h}$ at $4^{\circ} \mathrm{C}$. Non-specific binding was evaluated by incubating adjacent sections in the presence of $100 \mu \mathrm{M}$ noradrenaline. The binding reaction was terminated by washing the slides twice in TE buffer $\left(4^{\circ} \mathrm{C}\right)$ before rinsing in distilled water $\left(4^{\circ} \mathrm{C}\right)$. The sections were dried in a continuous stream of cold air, followed by air-drying overnight at room temperature $\left(\sim 22^{\circ} \mathrm{C}\right)$. A parallel series of experiments were conducted using $\left[{ }^{3} \mathrm{H}\right]-\mathrm{RX} 821002(2-25 \mathrm{nM})$ where nonspecific binding was evaluated in the presence of rauwolscine $(100-250 \mu \mathrm{M})$.

For low-resolution autoradiography, slidemounted sections were exposed to ${ }^{3} \mathrm{H}$ Hyperfilm (Amersham Biosciences, Little Chalfont, UK) in $\mathrm{X}$-ray cassettes for up to 9 weeks at $4^{\circ} \mathrm{C}$. Films were developed using Kodak D19 and fixed using Hypam (Ilford, Moberly, Cheshire, UK). For high-resolution autoradiography, sections were dipped in molten nuclear emulsion (K2, Ilford) following air-drying. The slides were stored in light-proof boxes containing dessicant at $4^{\circ} \mathrm{C}$ and processed once low-resolution (film) autoradiography provided evidence of binding to tissue sections. Following development, the sections were counterstained with haematoxylin and eosin, visualized using an Olympus BX50 microscope (Olympus Corporation, Tokyo, Japan) and photographed where appropriate on an AxioCam digital camera (Carl Zeiss MicroImaging $\mathrm{GmBH}$, Göttingen, Germany) with images stored on a KS300 imaging system (Imaging Associates, Bicester, UK).

\section{Contractile studies}

Following collections of the sheep anal tissue (as described above), a thin strip of circular internal sphincter measuring approximately $50 \mathrm{mM}$ long, $5 \mathrm{mM}$ wide and $2 \mathrm{mM}$ thick was removed and stored overnight in Krebs-Henseleit solution at $4^{\circ} \mathrm{C}$. The following day, tissue strips were allowed to warm up to room temperature. Additional connective tissue was removed by sharp dissection from the specimen, and up to a maximum of four strips of internal sphincter tissue (approximately $10 \times 2 \times 2 \mathrm{mM}$ ) containing visible parallel muscle fibres were prepared and used for experiments. Silk ligatures were tied to each end of the strips, and the lower end was attached to a perspex holder between two parallel platinum wire electrodes (although electrical field stimulation was not performed in this series of experiments). The upper end was secured to a Grass FT-03 isometric force transducer (Grass Technologies, West Warwick, RI, USA) ensuring some laxity in the suspended tissue which was bathed for approximately $30 \mathrm{~min}$ in $20 \mathrm{~mL}$ organ baths containing Krebs-Henseleit solution ( $\mathrm{pH} 7.4)$, gassed (95\% $\mathrm{O}_{2} / 5 \% \mathrm{CO}_{2}$ ) at $37^{\circ} \mathrm{C}$. The transducer was connected to a MacLab Bridge amplifier (AD Instruments, Chalgrove, UK) and linked via a four-channel MacLab unit to a Macintosh LC II computer running Chart 3.5.

The strips were initially placed under $19.62 \mathrm{mN}$ tension, which has previously been identified as an optimal stretch tension necessary for the development of spontaneous myogenic tone in sheep isolated IAS (Mundey et al., 2000). Once stable myogenic tone had been reached, cumulative concentration curves were constructed by half-logarithm increments using a total of six imidazoline compounds, which were compared to responses to the $\alpha$-adrenoceptor agonists L-erythro-methoxamine and noradrenaline. Only one agonist was used per strip. A minimum of $5 \mathrm{~min}$ was allowed between the addition of individual concentrations, and subsequent additions were made only after the previous response had reached equilibrium. In addition, the responses of L-erythro-methoxamine and clonidine were examined in the presence or absence of $100 \mathrm{nM}$ prazosin and $100 \mathrm{nM}$ RX-811059, antagonists selective for $\alpha_{1}$ - and $\alpha_{2}$-adrenoceptors, respectively (McGrath et al., 1989; Mallard et al., 1992). The antagonists were allowed to equilibrate for 30 min prior to construction of the concentration curve. 


\section{Data analysis}

For saturation binding experiments, $K_{\mathrm{d}}$ and $B_{\max }$ values were calculated using GraphPad Prism (GraphPad, San Diego, CA, USA) and represented as the mean \pm SEM for triplicate experiments. Competition binding curves were similarly constructed, and the mean $\mathrm{pK}_{\mathrm{i}}$ values \pm SEM for triplicate experiments calculated. In contractile studies, changes in tension with the addition of drugs were determined as the maximal increase or decrease in tone, and are expressed as a percentage of the initial stable myogenic tone. Individual concentration-response curves were constructed for each tissue, and the negative logarithm of the concentration required to achieve $50 \%$ of the maximum response $\left(\mathrm{pEC}_{50}\right)$ and the maximum response relative to myogenic tone $\left(R_{\max }\right)$ were calculated using GraphPad Prism. Differences between mean $\mathrm{pEC}_{50}$ and $R_{\max }$ values for L-erythromethoxamine and clonidine in the presence or absence of antagonists were compared using a oneway ANOVA with Dunnett's post hoc test and considered significant if $P<0.05$.

\section{Materials}

The composition of the modified Krebs-Henseleit saline was (in $\mathrm{mM}$ ): $\mathrm{NaCl} 118.4, \mathrm{KCl} 4.7, \mathrm{CaCl}_{2}$ 1.25, $\mathrm{MgSO}_{4} 1.2, \mathrm{NaHCO}_{3} 24.9, \mathrm{KH}_{2} \mathrm{PO}_{4} 1.2$, glucose 11.1. TE buffer was (in mM): Tris 50, EDTA 1, pH 7.4. The drugs used were obtained from Sigma-Aldrich (Poole, UK) with the exception of: prazosin hydrochloride (Pfizer, Sandwich, UK); 2-(2-ethoxy-1, 4-benzodioxan-2-yl)-2-imidazoline (RX-811059, Reckitts and Coleman, Hull, UK), L-erythromethoxamine (Norgine, Hengoed, UK), rauwolscine (Carl Roth GmbH \& Co. KG, Karlsruhe, Germany), moxonidine (Tocris Bioscience, Bristol, UK), xylometazoline (Chemos GmbH, Regenstauf, Germany), 5-methyl-3-[3-[3-[4-[2-(2,2,2, trifluroethoxy)phenyl]1-piperazinyl]propyl]-2,4-(1H,3H)-pyrimidinedione hydrochloride (RS100329, Tocris Bioscience), 8-[2[4-(methoxyphenyl)-1-piperazinyl] ethyl]-8-azaspir o[4.5]decane-7,9-dione dihydrochloride (BMY7378, Tocris Bioscience), 2-[(4,5-dihydro-1H-imidazol-2yl)methyl]-2,3-dihydro-1-methyl-1H-isoindole maleate (BRL44408, Tocris Bioscience).

$\left[{ }^{3} \mathrm{H}\right]-\mathrm{RX} 821002$ (2-methoxyidazoxan) and $\left[{ }^{3} \mathrm{H}\right]$-prazosin were obtained from GE Healthcare Ltd (Little Chalfont, UK). Prazosin (1 mM) was dissolved in $0.1 \mathrm{M}$ lactic acid. All further dilutions were made in distilled water. The concentration of the vehicle never exceeded $0.3 \% \mathrm{v} / \mathrm{v}$. All drug and molecular target nomenclature follows Alexander et al. (2009).

\section{Results}

\section{Radioligand binding}

Saturation binding. Figure 1 shows that $\left[{ }^{3} \mathrm{H}\right]-$ prazosin and $\left[{ }^{3} \mathrm{H}\right]-\mathrm{RX}-821002$ were able to bind to membranes of the sheep IAS in a concentrationdependent manner that was inhibited by $100 \mu \mathrm{M}$ noradrenaline and $100 \mu \mathrm{M}$ rauwolscine respectively. At the half-maximally effective concentration $\left(K_{\mathrm{d}}\right)$, approximately 87 and $90 \%$ of the binding of $\left[{ }^{3} \mathrm{H}\right]$-prazosin and $\left[{ }^{3} \mathrm{H}\right]-\mathrm{RX}-821002$, respectively, was inhibited. $\left[{ }^{3} \mathrm{H}\right]$-prazosin was calculated to have a $K_{\mathrm{d}}$ value of $0.58 \pm 0.07 \mathrm{nM}(n=3)$ and identified sites at density of $222 \pm 4 \mathrm{fmol} \cdot \mathrm{mg}^{-1}$ protein $(n=3)$, while $\left[{ }^{3} \mathrm{H}\right]-\mathrm{RX} 821002$ was slightly less potent $\left(K_{\mathrm{d}}=\right.$ $0.7 \pm 0.14 \mathrm{nM}, n=3$ ) and labelled approximately one-third the number of sites $\left(72 \pm 7 \mathrm{fmol} \cdot \mathrm{mg}^{-1}\right.$ protein, $n=3$ ). These findings indicate that the sheep isolated IAS possesses both $\alpha_{1^{-}}$and $\alpha_{2^{-}}$ adrenoceptor binding sites.

Discrimination of $\alpha$-adrenoceptor sub-type using radioligand binding. Competition binding analysis was subsequently used to investigate which sub-type of $\alpha$-adrenoceptor was identified by each ligand in this tissue. The $\mathrm{pK}_{\mathrm{i}}$ values for the competing agents generated from these experiments are summarized in Table 1. With the exception of RS100329, all of the Hill slope values were close to unity $(>0.8)$. In each instance, the competing agents displaced $>90 \%$ of the specific binding of the ligands (data not shown). RS100329 (an $\alpha_{1 \mathrm{~A}}$-adrenoceptor-selective antagonist; Williams et al., 1999), 5-methyl-urapidil (discriminates $\alpha_{1 \mathrm{~A}}$ from $\alpha_{1 \mathrm{~B}} / \alpha_{1 \mathrm{D}}$-adrenoceptor sub-types; Ford et al., 1997) and BMY7378 ( $\alpha_{1 \mathrm{D}}$-adrenoceptor subtype-selective antagonist; Piascik et al., 1995) were used to investigate the sub-type of $\alpha_{1}$-adrenoceptor present in sheep IAS. The data summarized in Table 1 indicate that the rank order of affinity for these agents is 5-methylurapidil $\geq \mathrm{RS} 100329>$ BMY7378, suggesting the presence of the $\alpha_{1 \mathrm{~A}^{-}}$ adrenoceptor sub-type.

Four agents were used to provide information on the $\alpha_{2}$-adrenoceptor sub-type present. BRL44408 was used as a selective $\alpha_{2 \mathrm{~A}} / \alpha_{2 \mathrm{D}}$-adrenoceptor antagonist (Wikberg-Matsson et al., 1995); prazosin, although non-selective at $\alpha_{1}$-adrenoceptor subtypes, can be employed to discriminate between $\alpha_{2 C^{-}}$ adrenoceptors (for which it has high affinity) and $\alpha_{2 \mathrm{~A}} / \alpha_{2 \mathrm{D}}$-adrenoceptors (McGrath et al., 1989); phentolamine and rauwolscine were also used, as the relative affinities of these two agents can be used to discriminate between $\alpha_{2 \mathrm{~A}^{-}}$and $\alpha_{2 \mathrm{D}}$-adrenoceptor sub-types. If the affinity of rauwolscine is greater than phentolamine, it is indicative of the presence 

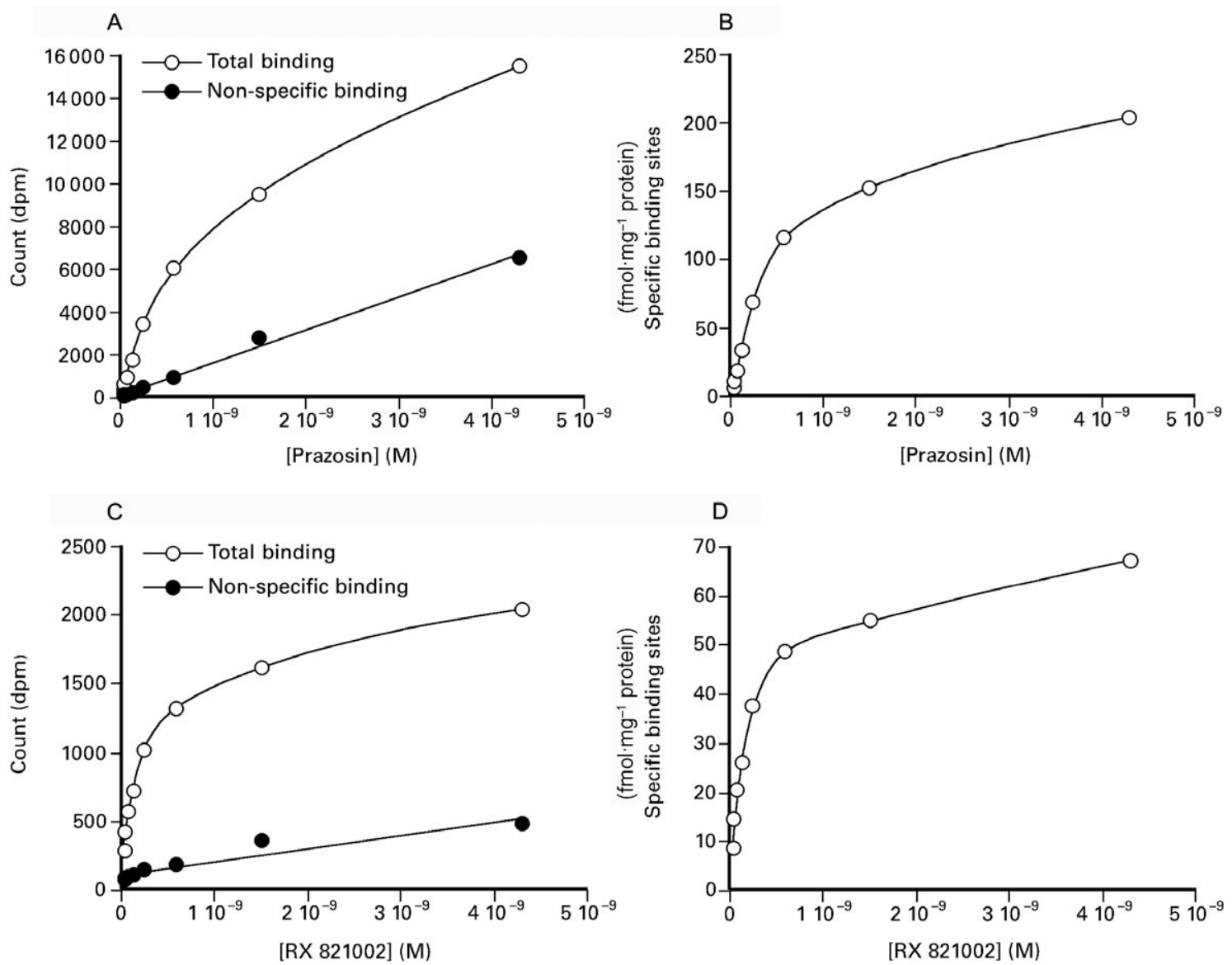

\section{Figure 1}

Saturation binding data for $\left[{ }^{3} \mathrm{H}\right]$-prazosin $(A, B)$ and $\left[{ }^{3} \mathrm{H}\right]-\mathrm{RX}-821002(\mathrm{C}, \mathrm{D})$. Representative data showing total and non-specific binding from a single experiment are shown in (A) for $\left[{ }^{3} \mathrm{H}\right]$-prazosin and $(C)$ for $\left[{ }^{3} \mathrm{H}\right]$-RX821002. (B) and (D) show representative specific binding curves from a single experiment using $\left[{ }^{3} \mathrm{H}\right]$-prazosin and $\left[{ }^{3} \mathrm{H}\right]-\mathrm{RX} 821002$ respectively.

\section{Table 1}

Mean $\mathrm{pK}_{\mathrm{i}}$ values ( \pm SEM of three experiments) for sub-type-selective inhibitors at $\alpha_{1}-\left(\left[{ }^{3} \mathrm{H}\right]\right.$-prazosin) or $\alpha_{2}$-adrenoceptors $\left(\left[{ }^{3} \mathrm{H}\right]-\mathrm{RX} 821002\right)$ on sheep IAS

\begin{tabular}{|c|c|c|}
\hline & $\mathrm{pK}_{\mathrm{i}}$ (Hill slope) [3 H]-RX-821002 & $\mathrm{pK}_{\mathrm{i}}$ (Hill slope) $\left[{ }^{3} \mathrm{H}\right]$-prazosin \\
\hline RS100329 & $n / d$ & $9.14 \pm 0.11(-0.68 \pm 0.06)$ \\
\hline 5-Methyl-urapidil & $\mathrm{n} / \mathrm{d}$ & $9.52 \pm 0.03(-1.27 \pm 0.08)$ \\
\hline BMY7378 & $n / d$ & $6.61 \pm 0.04(-0.98 \pm 0.09)$ \\
\hline BRL44408 & $8.85 \pm 0.13(-0.81 \pm 0.06)$ & $n / d$ \\
\hline Prazosin & $5.32 \pm 0.13(-1.07 \pm 0.09)$ & $n / d$ \\
\hline Rauwolscine & $7.91 \pm 0.12(-0.83 \pm 0.08)$ & $\mathrm{n} / \mathrm{d}$ \\
\hline Phentolamine & $8.66 \pm 0.08(-0.84 \pm 0.07)$ & $n / d$ \\
\hline
\end{tabular}

$\mathrm{n} / \mathrm{d}$, the experiment was not done.

of an $\alpha_{2 \mathrm{~A}}$-adrenoceptor; if the affinity of phentolamine is greater than rauwolscine, then an $\alpha_{2 D^{-}}$ adrenoceptor is implied (Trendelenburg et al., 1996; Naselsky et al., 2001). The data summarized in
Table 1 indicate that the rank order of affinity for these agents is BRL44408 > phentolamine > rauwolscine $>$ prazosin, which is consistent with the presence of $\alpha_{2 \mathrm{D}}$-adrenoceptors. 
Table 2

Mean $\mathrm{pK}_{\mathrm{i}}$ values ( \pm SEM of three experiments) for imidazoline compounds at both $\alpha_{1}-\left(\left[{ }^{3} \mathrm{H}\right]\right.$-prazosin) and $\alpha_{2}$-adrenoceptor $\left(\left[{ }^{3} \mathrm{H}\right]\right.$ - $\left.\mathrm{RX}-821002\right)$ on the sheep IAS

\begin{tabular}{|llll} 
& $\mathbf{p K}_{\mathbf{i}}$ (Hill slope) $\left.\mathbf{~}^{\mathbf{3}} \mathbf{H}\right]-\mathbf{R X} \mathbf{- 8 2 1 0 0 2}$ & $\mathbf{p K}_{\mathbf{i}}$ (Hill Slope) $\left.\mathbf{~}^{\mathbf{3}} \mathbf{H}\right]$-prazosin & $\boldsymbol{\alpha}_{\mathbf{2}} / \boldsymbol{\alpha}_{\mathbf{1}} \mathbf{R a t i o}$ \\
\hline Naphazoline & $7.99 \pm 0.01(-0.79 \pm 0.01)$ & $6.84 \pm 0.09(-1.04 \pm 0.08)$ & 14 \\
Clonidine & $7.55 \pm 0.09(-0.91 \pm 0.07)$ & $6.39 \pm 0.10(-0.95 \pm 0.02)$ & 14 \\
Oxymetazoline & $7.23 \pm 0.09(-0.94 \pm 0.02)$ & $7.67 \pm 0.13(-0.87 \pm 0.05)$ & 0.36 \\
Xylometazoline & $6.92 \pm 0.05(-1.07 \pm 0.10)$ & $7.10 \pm 0.15(-0.82 \pm 0.04)$ & 0.6 \\
Tizanidine & $6.75 \pm 0.03(-0.82 \pm 0.04)$ & $5.57 \pm 0.05(-0.76 \pm 0.03)$ & 15 \\
Rilmenidine & $6.45 \pm 0.04(-0.87 \pm 0.05)$ & $5.33 \pm 0.04(-0.89 \pm 0.05)$ & 13 \\
Moxonidine & $5.98 \pm 0.06(-0.75 \pm 0.05)$ & $4.62 \pm 0.02(-0.88 \pm 0.02)$ & 23 \\
Noradrenaline & $5.62 \pm 0.08(-0.90 \pm 0.14)$ & $5.47 \pm 0.06(-0.83 \pm 0.02)$ & 1.4 \\
L-Erythro-methoxamine & $4.00 \pm 0.03(-0.99 \pm 0.08)$ & $5.40 \pm 0.07(0.86 \pm 0.04)$ & 0.04 \\
\hline
\end{tabular}

Competition binding with agonists. All of the putative agonists examined using competition binding showed concentration-dependent displacement of both radioligands and, with the exception of tizanidine $\left(\left[{ }^{3} \mathrm{H}\right]\right.$-prazosin) and moxonidine $\left(\left[{ }^{3} \mathrm{H}\right]-\mathrm{RX}\right.$ 821002), the Hill slope values were close to unity $(>0.8)$. The $\mathrm{pK}_{\mathrm{i}}$ values for these compounds are included in Table 2. The affinity of the imidazoline compounds against $\left[{ }^{3} \mathrm{H}\right]$-prazosin varied a 1000fold, with oxymetazoline and moxonidine the most and least potent respectively. Against $\left[{ }^{3} \mathrm{H}\right]$-RX821002 binding sites, a 100-fold range in potency was observed between the imidazoline derivatives (Table 2).

The ratio of mean $\left[{ }^{3} \mathrm{H}\right]-\mathrm{RX} 821002$ and $\left[{ }^{3} \mathrm{H}\right]-$ prazosin $\mathrm{pK}_{\mathrm{i}}$ values $\left(\alpha_{2}: \alpha_{1}\right.$ adrenoceptor binding) was used to establish receptor selectivity of agonists. Based on this analysis, a ratio with a value higher than 1 indicates an $\alpha_{2}$-selective agonist, whereas a value of less than 1 suggests an $\alpha_{1}$-adrenoceptor selective agent. The majority of the agonists exhibited 3- to 30-fold selectivity for $\alpha_{2}$-adrenoceptor binding sites over $\alpha_{1}$-adrenoceptor binding sites, with moxonidine exhibiting the greatest selectivity. In contrast, L-erythro-methoxamine possessed 25 -fold greater selectivity for $\alpha_{1}$-adrenoceptor binding sites (Table 2). Noradrenaline, xylometazoline and oxymetazoline did not distinguish between the $\alpha_{1}$ - and $\alpha_{2}$-adrenoceptor binding sites.

\section{Immunohistochemistry}

Sections of sheep IAS that had been exposed to the anti- $\alpha$-smooth muscle actin antibody and counterstained with haematoxylin showed a pronounced positive staining (red colouration) throughout the tissue (Figure 2A,B). The staining was most intense in bundles surrounded by a loose network of pale pink-stained tissue.
Anti-CD31 antibodies were used as a marker for the presence of endothelial tissue, and therefore indicative of the vasculature associated with the tissue sections of sheep IAS (Figure 2C,D). Unlike the smooth muscle actin, this antibody stained discrete areas of the tissue sections that appear to correspond to the areas of pale pink immunostaining surrounding the bundles of $\alpha$-smooth muscle actinrich tissue.

Two antibodies were used to identify neuronalderived tissue. As shown in Figure 2E,F, anti-NF200 was found to have a distribution of staining largely similar to anti-CD31 antibodies in the areas of weak $\alpha$-smooth muscle actin staining. However, closer examination of the tissue also revealed a weaker distribution of staining with anti-NF200 that also corresponds to the $\alpha$-smooth muscle actin-rich bundles of tissue. In addition to NF200, an antityrosine hydroxylase antibody was also used to identify adrenergic nerves. The profile of intense staining was similar to that observed using the NF200 antibody, where positive staining was observed in both the $\alpha$-smooth muscle actin-rich tissue and surrounding tissue which was weakly stained by the $\alpha$-smooth muscle actin antibody (Figure $2 \mathrm{G}, \mathrm{H}$ ). In the absence of primary antibody, the slides revealed a low level of staining (pale pink) that corresponded to the $\alpha$-smooth muscle actinpoor regions of the tissue (Figure 2I,J).

Based on the results of $\alpha_{1}$-adrenoceptor sub-type competition binding, sections of sheep and human IAS were also incubated with an $\alpha_{1 \mathrm{~A}}$-adrenoceptor antibody. Results using this antibody can be seen in Figure 3 with their corresponding negative controls. Overall, both tissues showed a similar distribution of positive staining: with a diffuse pink positive staining over the smooth muscle bundles, as well as discrete areas of dense positive staining which could 
A

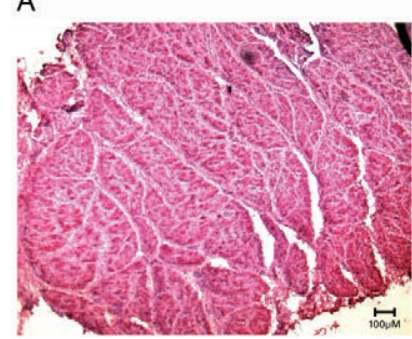

C

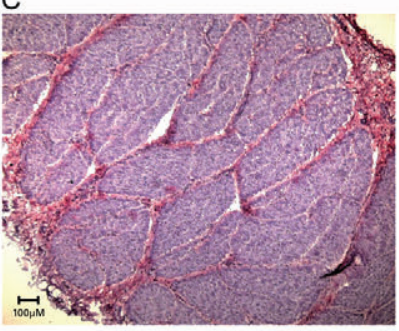

E

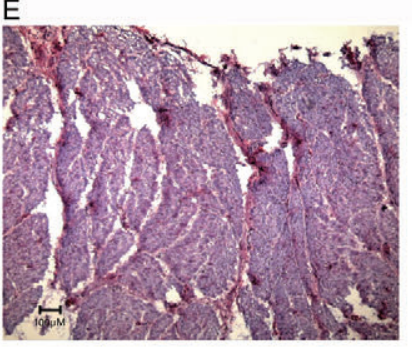

G

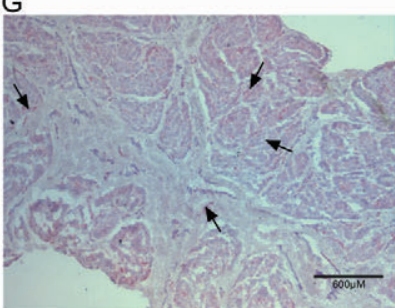

I

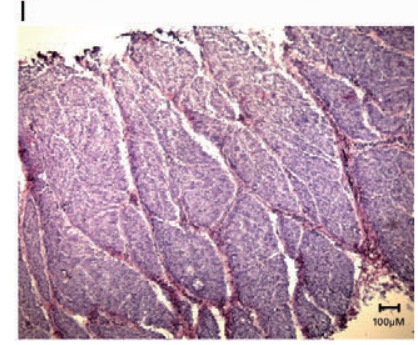

B

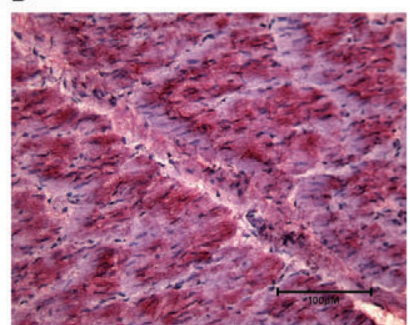

D

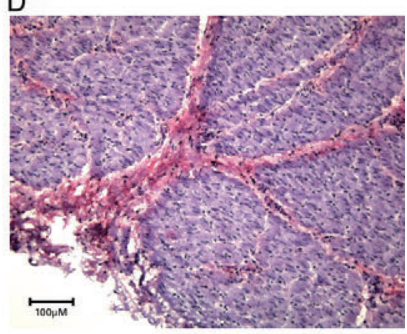

$\mathrm{F}$

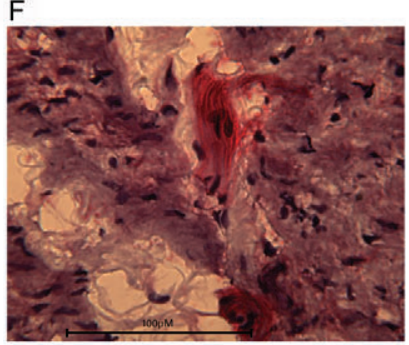

$\mathrm{H}$
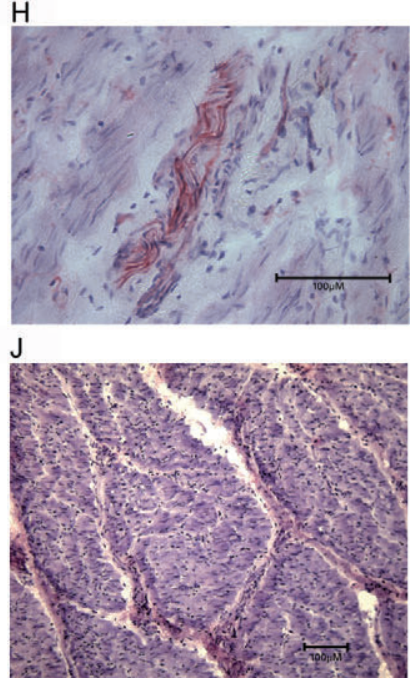

\section{Figure 2}

Anti- $\alpha$-smooth muscle actin antibody at low $(A)$ and high magnification (B); CD31 antibody at low (C) and higher magnification (D); NF200 antibody at low (E) and high magnification (F); tyrosine hydroxylase antibody at low $(\mathrm{G})$ and high magnification $(\mathrm{H})$; negative control (no primary antibody) at low (I) and high magnification (J). Arrows are used to indicate dense areas of positive staining in Figure $2(\mathrm{G})$. Positive immunostaining is red and sections counterstained with haematoxylin (blue).

be found either in or between the muscle bundles. This discrete dense staining was particularly apparent in the human specimens.

\section{Autoradiography}

Using $5 \mathrm{nM}\left[{ }^{3} \mathrm{H}\right]$-prazosin, significant binding was observed in sheep IAS after 8 weeks exposure (a typical example is shown in Figure 4). Specific binding occurs in discrete areas of smooth muscle bundles, with no specific binding observed in connective tissue between smooth muscle bundles or adventitia (Figure 4A,B). Attempts to generate comparable images with $2-25 \mathrm{nM}\left[{ }^{3} \mathrm{H}\right]-\mathrm{RX}-821002$ were unsuccessful. Even after 12 weeks exposure, no evidence of $25 \mu \mathrm{M}\left[{ }^{3} \mathrm{H}\right]$-RX821002 rauwolscinesensitive 'hotspots' were observed $(n=3)$, although specific binding could be observed using sections of rat brain as positive controls incubated under the same conditions (data not shown).

\section{Contractile experiments}

The sheep IAS responded to the initial stretch with the generation of sustained increase tension above baseline (35.61 $\pm 2.84 \mathrm{mN}, n=28)$. All of the compounds examined elicited slow concentrationdependent contractions that took 5-10 min to attain a peak response that declined slowly thereafter. Rilmenidine was not investigated in detail because initial experiments revealed that the maximum response was not appreciably different from the other imidazoline derivatives (data not shown). Moreover, the sub-type selectively displayed in the radioligand binding experiments was comparable to clonidine and tizanidine (see Table 2). Based on the $\mathrm{pEC}_{50}$ values (Table 3), there was less than a 10-fold difference in potency between all six of the imidazoline compounds tested; in the case of moxonidine, many preparations failed to produce a true maximum response so the $\mathrm{pEC}_{50}$ values shown is an estimate. Xylometazoline was the most potent imidazoline agonist, which was between 10- and 100-fold more potent than L-erythro-methoxamine and noradrenaline, respectively (Table 3). Although L-erythro-methoxamine and noradrenaline were less potent than the imidazoline derivatives, the maximum responses were significantly larger (see Table 3); based on the increase in tone calculated relative to the baseline tone (\% of resting tone), the response to L-erythromethoxamine was approximately twofold greater than that elicited by clonidine (Student's unpaired $t$-test, $P<0.01$ ).

Figure 5A shows cumulative concentration curves for L-erythro-methoxamine in the presence or absence of $100 \mathrm{nM}$ prazosin (a selective $\alpha_{1}$-adrenoceptor antagonist) or $100 \mathrm{nM}$ RX-811059 
A

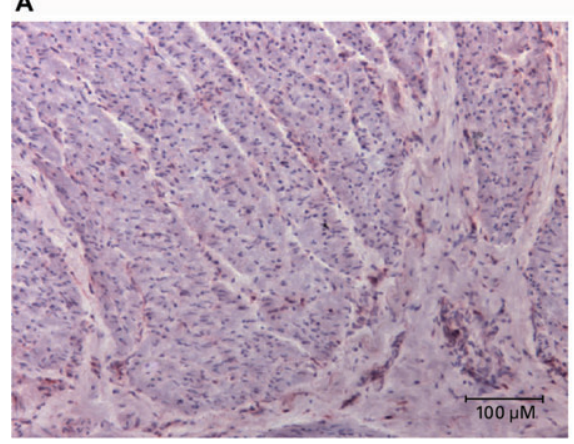

c

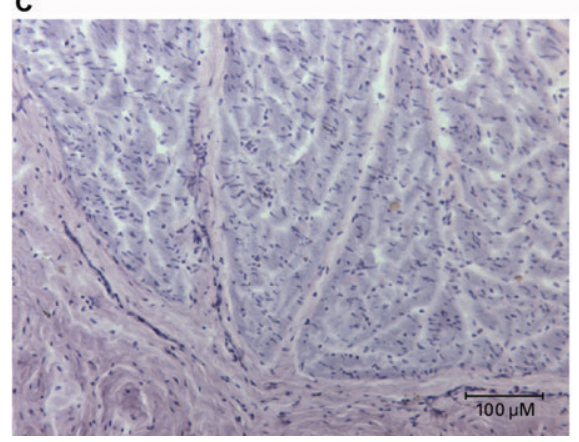

B

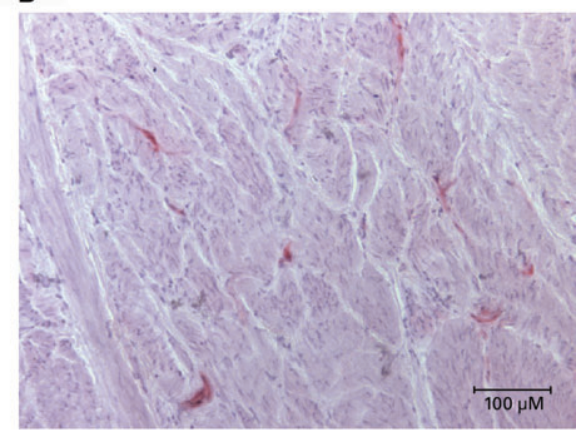

D

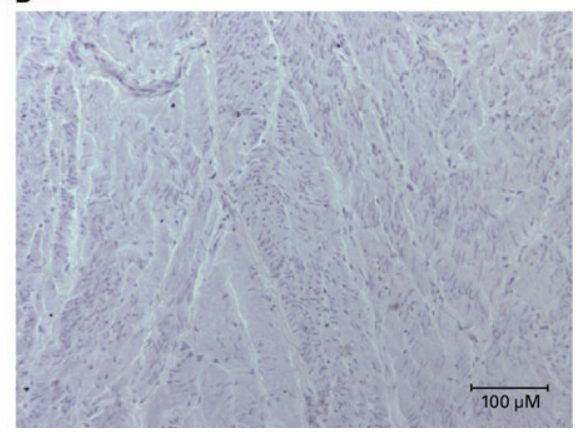

\section{Figure 3}

Comparison of staining using anti- $\alpha_{1 A}$-adrenoceptor antibody in sheep (A) and human (B) IAS at high magnification. Negative controls (no primary antibody) are also shown for sheep (C) and human (D) tissues. Positive immunostaining is pink or red, with haematoxylin counterstaining (blue).

A

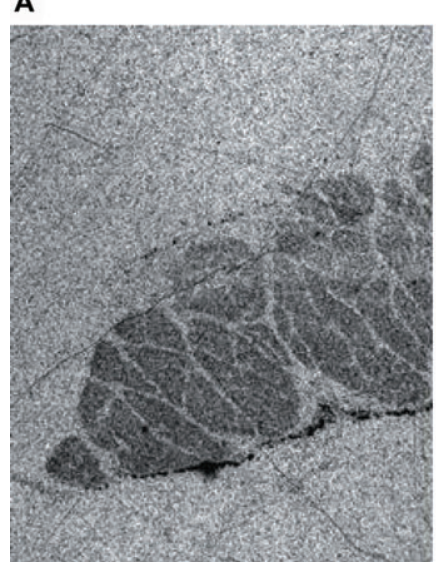

B

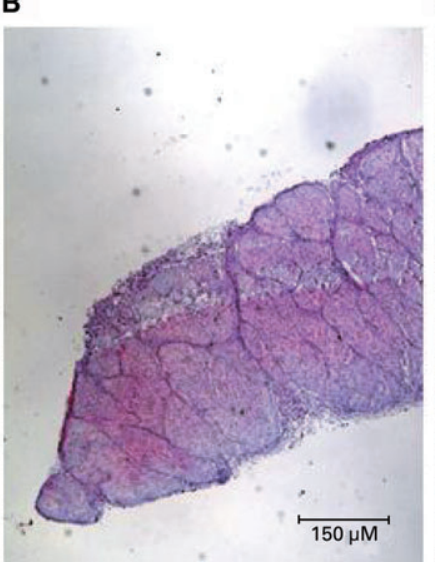

C

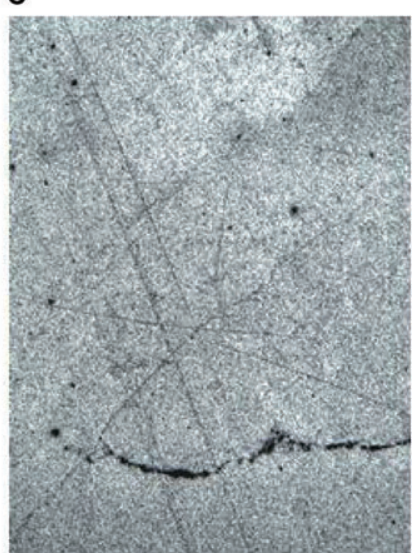

\section{Figure 4}

Film images showing the localization of ${ }^{3} \mathrm{H}$-prazosin binding in sections of sheep IAS: (A) Total binding of 5 nM ${ }^{3} \mathrm{H}$-prazosin to sheep IAS with some areas of dense binding. (B) Tissue underlying total binding, counterstained with haematoxylin and eosin. (C) Non-specific binding of $5 \mathrm{nM}$ ${ }^{3} \mathrm{H}$-prazosin in the presence of $100 \mu \mathrm{M}$ noradrenaline. These images are representative of sections taken from three individual sheep IASs.

(a selective $\alpha_{2}$-adrenoceptor antagonist). Contractile responses observed in the presence of $100 \mathrm{nM}$ RX-811059 did not differ significantly in terms of $\mathrm{pEC}_{50}$ (control $5.63 \pm 0.09, n=14$; RX-811059 5.43 $\pm 0.10, n=9$ ) or maximum contraction (control $50.72 \pm 5.59 \mathrm{mN}, n=14 ; \operatorname{RX811059} 56.31 \pm$ $3.83 \mathrm{mN}, n=9$ ) from those observed in control experiments. In contrast, $100 \mathrm{nM}$ prazosin caused a 30-fold rightward displacement of the concentration response curve to L-erythro-methoxamine; at the highest concentration of the agonist employed $(100 \mu \mathrm{M})$, there was a significant reduction in the response (control $136 \pm 18 \%, n=14$; prazosin $59 \pm$ $15 \%, n=12$; Student's paired $t$-test $P<0.005)$. 


\section{SJ Rayment et al.}

Table 3

The potency of imidazoline agonists, noradrenaline and L-erythro-methoxamine as contractile agents in sheep IAS

\begin{tabular}{|c|c|c|c|c|}
\hline & $\mathrm{pEC}_{50}$ & $R_{\max }(\mathbf{m} \mathbf{N})$ & $\begin{array}{l}\text { Maximal responses ( } \% \\
\text { of resting tone) }\end{array}$ & $n$ \\
\hline Xylometazoline & $6.89 \pm 0.06$ & $21.88 \pm 5.49$ & $63 \pm 23$ & 7 \\
\hline Naphazoline & $6.78 \pm 0.36$ & $19.13 \pm 2.84$ & $58 \pm 13$ & 10 \\
\hline Oxymetazoline & $6.46 \pm 0.20$ & $28.15 \pm 7.26$ & $57 \pm 13$ & 9 \\
\hline Clonidine & $6.44 \pm 0.07$ & $30.51 \pm 4.22$ & $62 \pm 7$ & 14 \\
\hline Tizanidine & $6.01 \pm 0.17$ & $27.37 \pm 5.79$ & $102 \pm 37$ & 7 \\
\hline Moxonidine & $5.22 \pm 0.11$ & $19.91 \pm 4.02$ & $67 \pm 10$ & 7 \\
\hline L-Erythro-methoxamine & $5.60 \pm 0.08$ & $42.58 \pm 4.91$ & $133 \pm 17$ & 20 \\
\hline Noradrenaline & $4.68 \pm 0.29$ & $34.14 \pm 5.20$ & $214 \pm 57$ & 5 \\
\hline
\end{tabular}

Values shown are the mean \pm SEM.

Cumulative concentration curves for clonidine in the presence or absence of $100 \mathrm{nM}$ prazosin and $100 \mathrm{nM}$ RX811059 are shown in Figure 5B. Both antagonists significantly affected the $\mathrm{pEC}_{50}$ values calculated compared to control (control $6.55 \pm$ $0.10, n=8$; prazosin $4.52 \pm 0.52, n=9$; RX811059 $6.03 \pm 0.16, n=8$ ) based on analysis by one-way ANOVA with Dunnett's post hoc test (prazosin $P<0.01 ;$ RX811059 $P<0.05)$. Neither antagonist affected the $R_{\max }$ values observed (control $37.57 \pm$ $5.40 \mathrm{mN}, n=8$; prazosin $43.65 \pm 9.03 \mathrm{mN}, n=9$; $\mathrm{RX811059} 34.43 \pm 4.91 \mathrm{mN}, n=8)$.

\section{Discussion}

\section{Presence and distribution of $\alpha$-adrenoceptors in the sheep IAS}

Saturation binding analysis of membrane preparations of the sheep IAS with $\left[{ }^{3} \mathrm{H}\right]$-prazosin and $\left[{ }^{3} \mathrm{H}\right]-\mathrm{RX} 821002$ revealed the presence of two discrete populations of $\alpha$-adrenoceptor binding sites. The density of $\alpha_{1}$-adrenoceptor binding sites was approximately threefold greater than that of $\alpha_{2}$ adrenoceptor binding sites.

Using sub-type-selective $\alpha_{1}$-adrenoceptor antagonists, the rank order of affinity against $\left[{ }^{3} \mathrm{H}\right]$-prazosin binding in the sheep IAS was RS100329 $\geq$ 5-methylurapidil $\gg$ BMY7378. Based on the published data for recombinant human receptors (McGrath et al., 1989; Mallard et al., 1992), the rank order of affinity is consistent with that described for the $\alpha_{1 \mathrm{~A}}$-adrenoceptor sub-type. This conclusion is in agreement with recent observations in the pig isolated IAS where RS100329 was reported to competitively inhibit phenylephrine-induced contractions with a $\mathrm{pA}_{2}$ value of 9.0 (Mills et al., 2008).
For the population of $\alpha_{2}$-adrenoceptor binding sites, sub-type-selective antagonists suggested the presence of $\alpha_{2 D}$-adrenoceptors. This conclusion is based on the finding that BRL4408 showed high affinity $\left(\mathrm{pK}_{\mathrm{i}} 8.85\right)$ against $\left[{ }^{3} \mathrm{H}\right]-\mathrm{RX} 821002$ binding, while prazosin was only weakly active (see Table 1), which suggests the presence of the $\alpha_{2 \mathrm{~A} / \mathrm{D}^{-}}$ adrenoceptor. These species orthologues of $\alpha_{2^{-}}$ adrenoceptors can be distinguished on the basis of the relative potency of phentolamine and rauwolscine (Trendelenburg et al., 1996; Naselsky et al., 2001). As phentolamine was approximately fivefold more potent than rauwolscine, the sub-type present in sheep is similar to that found in the rat and cow $\left(\alpha_{2 \mathrm{D}}\right.$-adrenoceptor) rather than that previously described in man and pig ( $\alpha_{2 \mathrm{~A}}$-adrenoceptor). As far as we are aware, the available data suggest that the two species orthologues respond in a similar manner to known $\alpha_{2}$-adrenoceptor agonists, so the functional significance of this difference is unclear.

Immunohistochemical analysis revealed that the sheep IAS is composed of bundles of smooth muscle fibres. Interestingly, the smooth muscle-poor regions of the tissue were highly stained by antibodies to CD31 and NF200, which suggests that vascular endothelium and enteric nerves are closely associated with connective tissue that links the bundles of smooth muscles. The finding that positive staining for adrenergic nerves (using a tyrosine hydroxylase antibody) can be identified in close association with the smooth muscle bundles is consistent with adrenergic innervation of the IAS as observed in sheep (Acheson et al., 2009). Autoradiographic studies with $\left[{ }^{3} \mathrm{H}\right]$-prazosin revealed the presence of $\alpha_{1}$-adrenoceptor binding sites on the smooth muscle bundles that were largely absent from the smooth muscle-poor regions of the tissue. Positive staining 
A
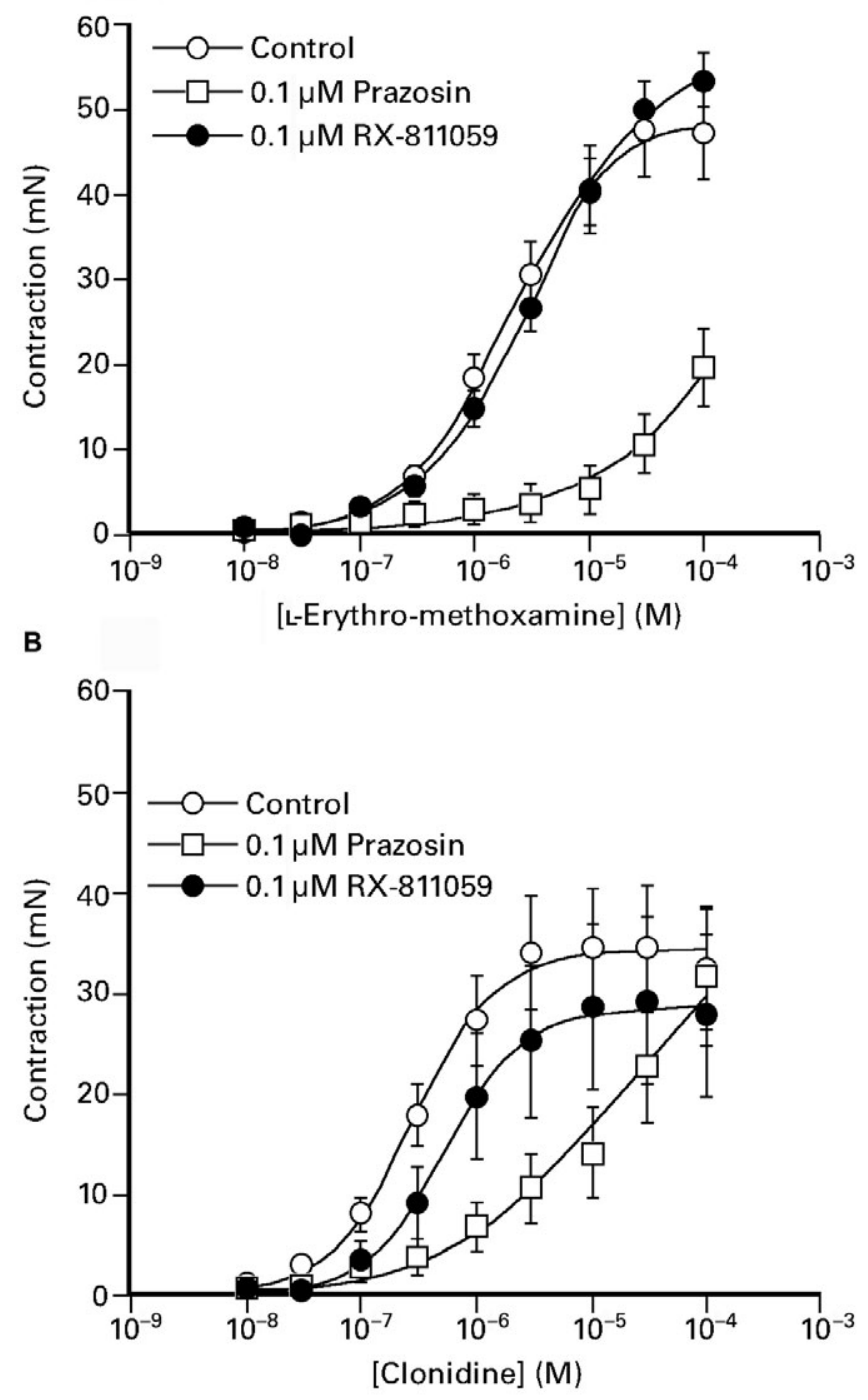

Figure 5

Comparison of the effect of (A) L-erythro-methoxamine and (B) clonidine on the sheep isolated IAS in the absence (control) and the presence of $0.1 \mu \mathrm{M}$ prazosin and $1 \mu \mathrm{M} \mathrm{RX}-811059$. The responses shown are the mean \pm SEM of 9-14 observations.

in smooth muscle bundles of human and sheep IAS was further confirmed using an antibody specifically targeting the $\alpha_{1}$-adrenoceptor sub-type indicated by radioligand binding experiments $\left(\alpha_{1 A^{-}}\right.$ adrenoceptors). In light of the pattern of adrenergic neurones revealed by the immunohistochemistry, confirmation of the presence of $\alpha_{1}$-adrenoceptors in sheep and human tissue lends further weight to the interpretation of adrenergic innervation.

Surprisingly, the distribution of $\alpha_{2}$-adrenoceptor binding sites could not be revealed by this method. Even with several modifications to the protocol, including elevation of the concentration of $\left[{ }^{3} \mathrm{H}\right]$ RX821002 to 10 -fold greater than the $K_{\mathrm{d}}$ value, elevation of the concentration of rauwolscine (the displacing agent) to $100 \mu \mathrm{M}$ and increased duration of exposure of the tissue segments to the film, no specific binding was detected. In contrast, 'hot spots' of $\left[{ }^{3} \mathrm{H}\right]-\mathrm{RX} 821002$ binding sites was observed in slices of the rat cerebral cortex (approx' $250 \mathrm{fmol} \cdot \mathrm{mg}^{-1}$ protein) when run in parallel experiments (unpublished observations). Thus, it seems likely that the low density of $\alpha_{2}$-adrenoceptor binding sites in the sheep IAS precludes autoradiographic detection.

\section{The activity of imidazoline derivatives compounds at $\alpha$-adrenoceptors}

Three observations prompted a detailed study of biological activity of imidazoline derivatives in the sheep IAS. First, clinical evidence that the greater potency of L-erythro-methoxamine at $\alpha_{1}$ adrenoceptors, compared to phenylephrine, allowed for low concentrations to be used to raise anal sphincter pressure in volunteers and patients (Carapeti et al., 1999; 2000; Cheetham et al., 2001; Badvie and Andreyev, 2005; Nisar et al., 2007; Park et al., 2007). Second, imidazoline derivatives (e.g. xylometazoline, and clonidine) are generally known as agonists at $\alpha$-adrenoceptors with greater potency than either noradrenaline or adrenaline, but possess varying selectivity for the sub-types (McGrath et al., 1989). Compounds in this class are used clinically as nasal decongestants, anti-hypertensive agents and anti-spasticity agents, and to reduce symptoms of opiate withdrawal. Third is the finding that anal sphincter smooth muscle possesses both $\alpha_{1}$ - and $\alpha_{2}$-adrenoceptor binding sites (see above). Thus, seven different imidazoline derivatives were examined in competition binding studies to determine their relative affinity at $\alpha_{1}$ - and $\alpha_{2}$-adrenoceptors in the anal sphincter.

With the exception of xylometazoline and oxymetazoline, all of the imidazoline derivatives exhibited a greater selectivity (>3-fold) for $\alpha_{2-}$ adrenoceptor binding sites over $\alpha_{1}$-adrenoceptor binding sites. In general, these compounds possessed a higher affinity (3- to 300-fold) at $\alpha_{2^{-}}$ adrenoceptor binding sites than either L-erythromethoxamine or noradrenaline. For the majority of compounds examined, the affinity at $\alpha_{2^{-}}$ adrenoceptor binding sites in the sheep IAS agrees with the known activity at recombinant human $\alpha_{2 \mathrm{~A}} /$ $\alpha_{2 \mathrm{D}}$-adrenoceptors expressed in HEK cells (Jasper et al., 1998). In contrast, at $\alpha_{1}$-adrenoceptor binding sites, the imidazoline derivatives can be divided into two groups: those with an affinity comparable to L-erythro-methoxamine and noradrenaline (tizanidine, rilmenidine and moxonidine) and those that 
possessed a 10-fold higher affinity (naphazoline, clonidine, oxymetazoline and xylometazoline).

Contraction-based experiments revealed that all the agents examined elicited concentrationdependent responses. A characteristic feature of the results is that the maximum responses for the imidazoline compounds were approximately $30 \%$ of that elicited by noradrenaline, an effect similar to that observed in other smooth muscle preparations that possess $\alpha_{1}$-adrenoceptors, such as rat aorta (Ruffolo and Waddell, 1982), porcine splenic artery (Barbieri et al., 1998) and human nasal mucosa (Johannssen et al., 1997). Also, with the exception of moxonidine, L-erythro-methoxamine and noradrenaline, the potency of the compounds was more closely related to the affinity detected against the $\alpha_{1}$-adrenoceptor binding sites. Confirmation of the predominant role of $\alpha_{1}$-adrenoceptors was obtained when examining the effect of sub-type-selective antagonists, prazosin and RX-811059, against L-erythro-methoxamine and clonidine-induced contractions. In each case, prazosin (100 nM) caused an approximate 30-fold rightward displacement of the concentration-response curve. However, while the selective $\alpha_{2}$-adrenoceptor antagonist RX-811059 (100 nM) was inactive against L-erythro-methoxamine-induced contractions, it caused a threefold rightward displacement of clonidine-induced contractions. The latter observation provides unambiguous evidence for the presence of $\alpha_{2}$-adrenoceptors on the smooth muscle of the sheep isolated internal sphincter and raises the possibility of a synergistic interaction with $\alpha_{1}$-adrenoceptors.

A functional role for $\alpha_{2}$-adrenoceptors in the control of defaecation has largely been confined to the enteric nervous system; by reducing the rate of gastrointestinal transit (Scheibner et al., 2002), interference in the ano-rectal inhibitory response in the opossum (Yamato and Rattan, 1990) and modulation of colonic and rectal compliance in man (Viramontes et al., 2001; Camilleri et al., 2003). The finding that $\alpha_{2}$-adrenoceptors are also present on the sphincter muscle and have the potential to enhance $\alpha_{1}$-adrenoceptor responses, may explain the observation in the anaesthetized opossum that naphazoline causes both increased IAS pressure and inhibited the recto-anal inhibitory response (Yamato and Rattan, 1990).

The original basis for examining the potential of L-erythro-methoxamine for treating faecal incontinence was the finding that it possessed approximately fourfold greater potency than phenylephrine (Jones et al., 2003). With the exception of moxonidine, all of the imidazoline derivatives examined in this study were more potent than L-erytho- methoxamine, but significantly less 'efficacious'. The impact of the latter property on their therapeutic potential is unclear, but it is noteworthy that many imidazoline derivatives have been successfully used as potent decongestants in man despite possessing significantly low constrictor 'efficacy' at $\alpha$-adrenoceptors in nasal blood vessels (Johannssen et al., 1997; Corboz et al., 2003).

In conclusion, we have demonstrated the presence of $\alpha_{1 \mathrm{~A}^{-}}$and $\alpha_{2 \mathrm{D}}$-adrenoceptors on the sheep IAS muscle. Although $\alpha_{1 \mathrm{~A}}$-adrenoceptors appear to make the major contribution to the constrictor effect of known $\alpha$-adrenoceptor agonists, in the case of selective $\alpha_{2}$-adrenoceptor imidazoline derivatives, there is the possibility of synergistic interaction between receptor sub-types. Because many imidazoline derivatives (e.g. clonidine) have greater potency at both $\alpha$-adrenoceptor sub-types compared to existing selective $\alpha_{1}$-adrenoceptor agonists, these agents could be effective at lower doses, thereby reducing the propensity for local or systemic side effects. In light of this, some imidazoline derivatives would be worthy candidates for investigating in the treatment of faecal incontinence.

\section{Acknowledgements}

We thank Woods Ltd, Clipstone, Nottinghamshire and $\mathrm{M}$ Najib and sons, Foston, Derbyshire for the supply of tissue.

\section{Conflict of interest}

None to declare.

\section{References}

Acheson A, Rayment S, Eames T, Mundey M, Nisar P, Scholefield J et al. (2009). Investigation of the role of adrenergic and non-nitrergic, non-adrenergic neurotransmission in the sheep isolated internal anal sphincter. Neurogastroenterol Motil 21: 335-345.

Alexander SPH, Mathie A, Peters JA (2009). Guide to Receptors and Channels (GRAC), 4th edn. Br J Pharmacol 158 (Suppl. 1): S1-S254.

Badvie S, Andreyev HJN (2005). Topical phenylephrine in the treatment of radiation-induced faecal incontinence. Clin Oncol 17: 122-126.

Barbieri A, Santagostino-Barbone MG, Zonta F, Lucchelli A (1998). Pharmacological characterization of alpha-adrenoceptors that mediate contraction in splenic artery strips from the pig. Naunyn Schmiedebergs Arch Pharmacol 537: 654-661. 
Camilleri M, Kim DY, McKinzie S, Kim H, Thormforde GM, Burton DD et al. (2003). A randomized controlled exploratory study of clonidine in diarrhea-predominant irritable bowel syndrome. Clin Gastroenterol Hepatol 1: 111-121.

Carapeti EA, Kamm MA, Phillips RKS (1999). Topical phenylephrine increases anal sphincter resting pressure. Br J Surg 86: 267-270.

Carapeti EA, Kamm MA, Phillips RKS (2000). Randomized controlled trial of topical phenylephrine in the treatment of faecal incontinence. Br J Surg 87: 38-42.

Cheetham MJ, Kamm MA, Phillips RK (2001). Topical phenylephrine increases anal canal resting pressure in patients with faecal incontinence. Gut 48: 356-359.

Corboz MR, Varty LM, Rizzo CA, Mutter JC, Rivelli MA, Wan Y et al. (2003). Pharmacological characterization of $\alpha_{2}$-adrenoceptors-mediated responses in pig nasal mucosa. Auton Autacoid Pharmacol 23: 208-219.

Ford APD, Daniels DV, Chang DJ, Gever JR, Jasper JR, Lesnick JD et al. (1997). Pharmacological pleiotropism of the human recombinant $\alpha_{1 \mathrm{~A}}$-adrenoceptor: implications for $\alpha_{1}$-adrenoceptor classification. Br J Pharmacol 127: 1127-1135.

Frenckner B, Ihre T (1976). Influence of autonomic nerves on the internal and sphincter in man. Gut 17: 306-312.

Glavind EB, Forman A, Tøttrup A (1997). Effects of transmural field stimulation in isolated smooth muscle of human rectum and internal anal sphincter. Am J Physiol 272: G1075-G1082.

Gutierrez JG, Shah AN (1975). Autonomic control of the internal anal sphincter in man. In: Trappen G (ed.). Vth International Symposium on Gastrointestinal Motility. Typoff Press: Leuven, pp. 363-373.

Jasper JR, Lesnick JD, Chang LK, Yamanishi SS, Chang TK, Hsu SA et al. (1998). Ligand efficacy and potency at recombinant $\alpha_{2}$-adrenergic receptors: agonist-mediated [35S]GTPgammaS binding. Biochem Pharmacol 55: 1035-1043.

Johannssen V, Maune S, Werner JA, Rudert H, Ziegler A (1997). Alpha 1- receptors at pre-capillary resistance vessels of the human nasal muscosa. Rhinology 35: 161-165.

Jones OM, Thompson JM, Brading AF, Mortensen NJ (2003). L-Erythro-methoxamine is more potent than phenylephrine in effecting contraction of internal anal sphincter in vitro. Br J Surg 90: 872-876.

Lowry OH, Rosebrough NJ, Farr AL, Randall RJ (1951). Protein measurement with the Folin phenol reagent. J Biol Chem 193: 265-275.

McGrath JC, Brown CM, Wilson VG (1989). $\alpha$-Adrenoceptors: a critical review. Med Res Rev 9: 408-531.

Mallard NJ, Hudson AL, Nutt DJ (1992).

Characterization and autoradiographical localization of non-adrenoceptor, idazoxan binding sites in the rat brain. Br J Pharmacol 106: 1019-1027.
Mills KA, Hausmann N, Chess-Williams R (2008). Characterization of the a1-adrenoceptor subtype mediating contraction of the pig internal anal sphincter. Br J Pharmacol 155: 110-117.

Mundey MKM, Jonas M, Worthley T, Scholefield JH, Wilson VG (2000). Pharmacological characterization of the neurogenic response of the sheep isolated internal anal sphincter. Br J Pharmacol 130: 489-494.

Naselsky DP, Ashton D, Ruffolo RR, Hieble JP (2001). Rabbit $\alpha_{2}$-adrenoceptors: both platelets and adipocytes $\alpha_{2 \mathrm{~A}}$-pharmacology. J Pharmacol Exp Ther 298: 219-225.

Nisar PJ, Gruss H-J, Bush D, Barras N, Acheson AG, Scholefield JH (2005). Intra-anal and rectal application of L-erythro methoxamine gel increases anal resting pressure in healthy volunteers. Br J Surg 92: 1539-1545.

Nisar PJ, Gruss H-J, Bush D, Acheson AG, Scholefield JH (2007). Intra-anal application of L-erythro methoxamine gel increases anal resting pressure in patients with incontinence. Br J Surg 94: 1155-1161.

Park JS, Kang SB, Kim DW, Namgung HW, Kim HL (2007). The efficacy and adverse effects of topical phenylephrine for anal incontinence after low anterior resection in patients with rectal cancer. Int J Colorectal Dis 22: 1319-1324.

Parks AG, Fishlock DJ, Cameron JD, May H (1969). Preliminary investigation of the pharmacology of the human internal anal sphincter. Gut 10: 674-677.

Perry S, Shaw C, McGrother C, Matthews RJ, Assassa RP, Dallosso H et al. (2002). Prevalence of faecal incontinence in adults aged 40 years or more living in the community. Gut 50: 480-484.

Piascik MT, Guarino RD, Smith MS, Soltis EE, Saussy DL, Perez DM (1995). The specifc contribution of the novel $\alpha_{1 \mathrm{~A}}$-adrenoceptor to the contraction of vascular smooth muscle. J Pharmacol Exp Ther 275: 1583-1589.

Pitt J, Dawson PM, Hallan RI, Boulos PB (2001). A double-blind radomized placebo-controlled trial of oral indoramin to treat chronic anal fissures. Colorectal Dis 3: $165-168$.

Ruffolo RR Jr, Waddell JE (1982). Receptor interactions of imidazolines: $\alpha$-adrenoceptors of rat and rabbit aortae differentiated by relative potencies, affinities and efficacies of imidazoline agonists. Br J Pharmacol 77: 169-176.

Scheibner J, Trendelenburg A-U, Hein L, Starke K, Blandizzi C (2002). $\alpha_{2}$-Adrenoceptors in the enteric nervous system: a study in $\alpha_{2 \mathrm{~A}}$-adrenoceptor deficient mice. Br J Pharmacol 135: 697-704.

Speakman CT, Hoyle CH, Kamm MA, Henry MM, Nicholls RJ, Burnstock G (1990). Adrenergic control of the internal anal sphincter is abnormal in patients with idiopathic faecal incontinence. Br J Surg 77: 1342-1344.

Trendelenburg A-U, Limberger N, Starke K (1996). The presynaptic alpha-2 autoreceptors in pig brain cortex are alpha2A. J Pharmacol Exp Ther 278: 462-467. 
Tuteja AK, Rao SS (2004). Review article: recent trends in diagnosis and treatment of faecal incontinence. Aliment Pharmacol Ther 19: 829-840.

Valet P, Senard J-S, Devedjian J-C, Planat V, Salomon R, Voisin T et al. (1993). Characterization and distribution of $\alpha_{2}$-adrenergic receptors in the human intestinal mucosa. J Clin Invest 91: 2049-2057.

Viramontes BE, Malcom A, Camilleri M, Szarka LA, McKinzie S, Burton DD et al. (2001). Effects of an $\alpha_{2}$-adrenergic agonist on gastrointestinal transit, colonic motility, and sensation in humans. Am J Physiol 281: G1468-G1476.

Wikberg-Matsson A, Wikberg JE, Uhlén S (1995). Identification of drugs subtype-selective for alpha 2A-, alpha 2B-, and alpha 2C-adrenoceptors in the pig cerebellum and kidney cortex. Eur J Pharmacol 284: 271-279.

Williams TJ, Blue DR, Daniels DV, Davis B, Elworthy T, Gever JR et al. (1999). In vitro $\alpha 1$-adrenocpetor pharmacology of Ro-70-0004 and RS-100329, novel $\alpha 1 \mathrm{~A}$-adrenoceptor selective antagonists. Br J Pharmacol 127: 252-258.

Wright IK, Blaylock NA, Kendall DA, Wilson VG (1995). The relationship between density of alpha-adrenoceptor binding sites and contractile responses in several porcine isolated blood vessels. Br J Pharmacol 114: 678-688.

Yamato S, Rattan S (1990). Role of alpha adrenoceptors in opossum internal anal sphincter. J Clin Invest 86: 424-429.

Zhang L, Keef KD, Bradley ME, Buxton ILO (1992). Action of $\alpha_{2}$-adrenergic receptors in circular smooth muscle of canine proximal colon. Am J Physiol 262 (Gastrointest Liver Physiol 25): G517-G524. 